\title{
Ways of Asking, Ways of Telling
}

\section{A Methodological Comparison of Ethnographic and Research Diagnostic Interviews}

\author{
Thomas J. Csordas • Christopher Dole • Allen Tran • \\ Matthew Strickland • Michael G. Storck
}

Published online: 17 December 2009

(C) The Author(s) 2009. This article is published with open access at Springerlink.com

\begin{abstract}
The interpretive understanding that can be derived from interviews is highly influenced by methods of data collection, be they structured or semistructured, ethnographic, clinical, life-history or survey interviews. This article responds to calls for research into the interview process by analyzing data produced by two distinctly different types of interview, a semistructured ethnographic interview and the Structured Clinical Interview for DSM, conducted with participants in the Navajo Healing Project. We examine how the two interview genres shape the context of researcher-respondent interaction and, in turn, influence how patients articulate their lives and their experience in terms of illness, causality, social environment, temporality and self/identity. We discuss the manner in which the two interviews impose narrative constraints on interviewers and respondents, with significant implications for understanding the jointly constructed nature of the interview process. The argument demonstrates both divergence and complementarity in the construction of knowledge by means of these interviewing methods.
\end{abstract}

\footnotetext{
T. J. Csordas $(\bowtie) \cdot$ A. Tran

Department of Anthropology, University of California, San Diego, 9500 Gilman Drive, La Jolla, CA 92093, USA 
Keywords Interview methodology - Narrative data - Sociolinguistics · Structured Clinical Interview for DSM · Ethnography · Navajo healing

The questions that you ask her seem to be real good and logical questions to ask a person about, a person having problems. She appreciates that. Then umm, in all the other interviews, they didn't. But somehow she got more out of this interview, questions, than the others. She said, it mixed up the working of her mind.

-Interpreter speaking for a 64-year-old female patient to psychiatrist (Structured Clinical Interview for DSM, Navajo Healing Project)

Interpretive understanding is highly influenced by whether interviews are structured, semistructured or open-ended, and whether they are intended to elicit ethnographic, clinical or life-history data (Babbie 1992; Bernard 1988; Denzin and Lincoln 1994; Fontanna and Frey 1994; Spradley 1979, 1980). Arguing specifically that research and clinical interviews constitute distinct genres of discourse, Mishler $(1975,1979,1984,1986)$ has examined, in a series of influential works, the effects on interview responses of variations in question wording, interview contexts, and interviewer characteristics. Criticizing the use of standardized survey instruments, he proposes an alternative approach to medical interviewing that recognizes that interviews are speech events, that interviews are jointly constructed by interviewers and respondents, that analysis and interpretation are based on a theory of discourse and meaning, and that the meaning of questions and answers are contextually grounded (Mishler 1986). These communicative standards "guide how individuals enter into situations, define and frame their sense of what is appropriate or inappropriate to say, and provide the basis for their understandings of what is said" (Mishler 1986:11). Echoing Mishler and posing important questions concerning the kinds of data ethnographic interviews produce, Briggs (1986) has similarly argued that interviews must be understood as communicative events and that researchers must more closely examine the compatibility between different styles of interviews as a means of acquiring information and the ways in which their subjects typically convey information to one another (such as story telling). Statements made during an interview should be considered in light of their performative context, not just as objective facts waiting for observation and the subsequent ascription of meaning by the investigators; not doing so blinds interviewers to potential errors in interpretation and to the limitations of the interview in acquiring data. The communicative interaction that occurs during an interview produces a discursive milieu in which understanding is made possible by a set of linguistic conditions determined by the interview.

This article takes up Mishler's and Briggs's call for additional research into the interview process. The methodological study we present here is a reflection on our work in the Navajo Healing Project (NHP), a study examining the experiential specificity of therapeutic change processes in three forms of religious healing in contemporary Navajo society: Traditional Navajo healing, Native American Church (NAC) healing and Navajo Christian faith healing (Csordas 2000, 2002; Csordas 
et al. 2008; Dole and Csordas 2003). In the NHP we conducted both semistructured ethnographic interviews (EIs) and the Structured Clinical Interview for DSM (SCID) with patients $(N=84)$ in religious healing. In our original design, the purpose of the SCID was simply to determine whether, from the standpoint of contemporary psychiatry, patients in religious healing would appear to have psychiatric disorders. This is similar to its typical use as a screening tool in psychiatric research, but we quickly realized that the SCID has far more narrative potential than is commonly recognized, and decided to audiotape the SCIDs as supplements to the EIs. Our determination to conduct the focused comparison of ethnographic and SCIDs reported here originates in the early recognition that we were in fact learning quite different things from the two interviews, things that substantially conditioned our interpretation. Specifically, our comparison was instigated by the case of a man who portrayed himself as a distinguished healer in EIs, and revealed in the SCID an ongoing struggle with alcohol abuse that placed his previous self-presentation in a significantly new light.

In light of this striking difference, we decided to undertake a systematic comparison of the interviews in a way that would both specify their sociolinguistic differences as speech events and underscore their substantive complementarity as elicitors of narrative. Framed in this way, we could go beyond the trivial recognition that instruments designed for different purposes and structured in different ways must differ, to accept the methodological challenge of elucidating precisely how they differ in their narrative dimension. To be precise, whereas the two modes of interviewing are so different that simply comparing their structure and purpose would lack academic or clinical interest, comparing them as interactive speech events is instrumental to advancing the understanding of how research interviewing taps, discloses, distorts or redirects human experience. For example, part of the distinctiveness between the interviews is produced as much by the participant's awareness that in the SCID the interlocutor is a physician, while in the EI the interlocutor is an anthropologist, as by the interview format or the content of specific questions. In this sense the present discussion examines how two interview genres shape the context of the researcher-patient interview exchange and, in turn, influence how patients articulate their lives and their experiences of illness and healing. We are concerned with how the different narrative constraints imposed on interviewers and respondents determine the jointly constructed nature of the interview process. In addressing these concerns we can add specificity to the observations made by Mishler and Briggs, showing, in the words of the patient quoted in our epigraph, the differences and similarities in how clinical and ethnographic interviews "mixed up the working of [participants'] mind[s]."

\section{Methodology of the Structured Clinical Interview for DSM-Ethnographic Interview Comparison}

The SCID is a semistructured interview administered by a mental health professional (psychiatrist or psychologist) for making DSM-IV diagnoses. The interview consists of an open-ended information-gathering component used to elicit 
a lifeline narrative and separate algorithmically structured modules exploring mood, thought, anxiety and substance use disorder symptoms across the patient's lifespan. The SCID assesses patients across four of the five dimensions (axes) of psychiatric clinical status (developmental and personality disorders are excluded): (1) primary psychiatric disorders; (2) relevant medical disorders; (3) severity of psychosocial stressors and (4) level of adaptive functioning (Spitzer et al. 1992). In our study, the SCID interviewer did not discourage extended answers and added several questions designed to elicit an elaboration of the patient's illness experience without altering the overall structure of the interview.

Our EIs combined a series of open-ended protocols including the Description of Illness in Navajo Experience (DINE) and the Context of Illness Experience Interview (CIEI), which cover demographics, family history and interpersonal environment, acculturation, work history, medical history, attitudes toward illness and health, explanatory model of the current illness, religious background, and experience with religious healing including sessions prior to the one observed. To elicit patient understandings of illness etiology, a component called the Interview for Causal Construal (ICC) was structured as a checklist to allow for elaboration when a particular causal factor was endorsed. The Interpersonal Process Recall (IPR) interview was adapted from a procedure developed by Elliot $(1984,1986)$ for use in psychotherapy process research, and focuses on the healing ritual observed by the researchers. The interview assesses therapeutic impact by asking the patient to identify the most significant event within a session and by eliciting an experiential commentary about that event. Finally, in follow-up interviews at intervals of approximately 3 months and 1 year, patients were asked for (a) accounts of what changes they have perceived in their problems since the healing ritual we observed; (b) the extent to which they perceive these changes as being attributable to the healing event observed; (c) accounts of any other ritual, medical or psychiatric intervention they have sought for their problem since then, and what they found significant about it; and (d) accounts of any other problems that have arisen since then for the patient or for a family member, and of what has been done to alleviate them.

The principal structural difference is that in the SCID, if a patient does not endorse the initial queries in a diagnostic module, the subsequent questions are not pursued, whereas in the EI all questions are asked. In the SCID questions are asked in a prescribed order, whereas in the EI the trajectory varies depending on the lead of the interviewee. There are temporal differences as well, foremost among which is that the EIs were conducted across a series of visits to the patients, whereas the SCID was a one-time event. Moreover, because of the logistics of arranging SCID interviews by a clinician who had to make periodic visits from off-reservation to conduct several interviews in the course of a few days, the SCID took place at varying moments within each patient's overall participation in the project.

To create a valid framework for comparing the two genres, we organized the interview data into 15 thematic categories: illness, symptom, cause, effect, treatment, identity statements, self characterizations, others' characterizations of patient, other people referred to by social role, proper names, reported speech, support, conflict, life problems and life events. To control for the fact that the texts 
of EIs were considerably longer than SCID interviews, we developed a quantitative measure of the relative number of unique references per thematic category. First, the number of unique items cataloged under a thematic category (i.e., the symptom category, the cause category, etc.) was summed for each interview. This sum was divided by the number of transcribed words in the corresponding interview and then multiplied by 10,000 , which produced a variable expressed as a count per 10,000 transcribed words. Each patient had two of these variables per thematic categoryone for the EI and one for the SCID interview. Subtracting a patient's SCID variable from the patient's ethnographic variable produced a difference score that was then used as the outcome variable in a paired $t$-test. The paired $t$-test was appropriate because each subject participated in two experimental conditions (the EI and the SCID), and the aim of the statistical analysis was to evaluate quantitative differences between interviews while controlling for the influence of the individual patient.

On the qualitative side of analysis, two coders individually examined each patient's ethnographic and SCID interview and generated a two-column table situating the thematic categories in a side-by-side manner with specific page references for each coded item. Coding focused principally on recording the presence of particular themes and their location within the transcribed text. Coders then utilized these tables to facilitate a second phase of analysis specifying the similarities and differences between the two interviews. In this stage of analysis, comparisons were prepared for each thematic category and for the interview as a whole. The result of this second-phase analysis was a written summary for each participant focusing on the following issues: whether interviewer or respondent initiated the topic; the degree to which topics were elaborated; patterns of turntaking among interviewer, patient and interpreter (when present); the role of other participants (when present), such as patients' family members; discursive circumstances in which stories were told (e.g., volunteered, elicited); evaluation of theme (as positive, negative, neutral); relative frequency of narratives produced by different types of speaker (e.g., male or female, elder or youth, Traditional/NAC/ Christian); role of interviewer as coproducer of narrative (e.g., by leading, probing, drawing patient back to the story); and performativity or manifest intent of stories (e.g., didactic, illustrative, edifying, clarifying, testifying, shocking). In the third phase, we compared these summaries, taking note of the degree to which patient narratives were consistent, inconsistent or contradictory across the two interview genres. In light of these analyses, in the presentation that follows we have combined our original 15 thematic categories into five more conceptually streamlined categories: Illness, Causality, Social Environment, Temporality and Identity/Self. We address each category in turn.

\section{Illness}

Given that interest in illness experience is the central feature common to the two interviews, the overarching difference in the narrative data they produced can be summarized in the formula that the EI tended to position the ill patient within a 
social world, and the SCID tended to position the illness within persons and their bodies. The SCID produced significantly more references to symptoms and effects of illness than the EI: SCIDs contained 6.25 more unique symptom references $(p<0.001)$ and 1.60 more unique effect references $(p=0.001)$ per 10,000 transcribed words. Because of the SCID's psychiatric orientation, psychological problems and the psychological dimension of physical illnesses tended to be more fully developed than in the EI, where they sometimes did not come up at all or were mentioned as one among a variety of problems.

For example, S.B., a 63-year-old man treated by Traditional Navajo healing, who names the same major illnesses (diabetes, eye problems and gallstones) in both interviews, nevertheless revealed far more symptoms consistent with depression in the SCID than in the EI. In the EI, in contrast, S.B. talks about how his diabetes has weakened him and left him unable to work and, thus, with constant financial worries. He says several times that he is "tired" of this and "tired" of needing help, but he does not discuss his emotional state in any more detail than that. In the SCID, however, when asked if he felt down every day, S.B. responded, "Yes, it seems like it's like that every day. Yes it seems like there is no way out in everything, and that is my situation. That's what I think." Responses elaborating on this feeling of being trapped, as well as fatigue, disturbed sleep, trouble concentrating and remembering span 6 pages of his 21-page SCID. Thus, in this case, the probing of the SCID's questions for symptoms of psychological problems yields a fairly complete picture of the interviewee's depression. S.B.'s demeanor was similar in both interviews; his responses (through interpreters) were equally thoughtful and direct and of comparable length. While the interpreters were not the same for the EI and the SCID, S.B.'s wife was present both times, clarifying his responses. Finally, relatively little time elapsed between interviews: the SCID was done on March 26, 1995, the EI on March 12, 1995, and a follow-up on March 31, 1995. In this case, it is clear that the SCID can isolate a response from its context, pursue it and develop a well-defined picture of depression that remains vague and understated in the EI.

Depending on the awareness of and amount of contact the interviewees have with biomedicine, their consciousness that the person administering the SCID is a psychiatrist, a physician, and a representative of the world of biomedicine may influence responses as much as the content and structure of the interview itself. One manifestation of participants' sense of what and how much is appropriate to say is the extent to which they distanced themselves or admitted vulnerability to an illness or problem. In the EI, participants were generally (1) more likely to list more than one major illness; (2) more likely to mention more symptoms, both related and unrelated to the major illness, and including a broader range of somatic/physical symptoms; (3) more likely to detail effects of the illness, such as the various aspects of physical pain and (4) more likely to reveal their feelings about their illness and symptoms. Physical symptoms were often mentioned in the SCID_-stripped of their emotional component.

For example, in her SCID C.P., a woman in Traditional Navajo healing, who suffered injuries in a car accident lists "soreness" and pain," "headaches" and being "slow in getting up." These are presented as being manageable. In the EI, however, she discusses these same physical symptoms, in addition to "fear of driving," "dreams" and not being able to get the accident out of her mind. C.P. mentions dreams in which 
she re-experienced the car accident in both the SCID and the EI. However, despite prompting from the interviewing psychiatrist, she did not acknowledge in the SCID that the dreams were upsetting. When asked if they were "distressing," she answered, "It was just about like a replay of what happened." In the EI, however, she described how the dream stayed with her after she woke up, how others said it was unusual to have such a dream after a ceremony and how she said a prayer at dawn to dispel the effects of the dream and to prevent having another one. What appears to be bravado about the illness and symptoms in the SCID may be the interviewee's understanding of what is appropriate to reveal to a biomedical physician, her sense that it is appropriate to isolate the illness or problem from its "unscientific" emotional or social context. Additionally, if interviewees wish to minimize the seriousness of an illness or understate a problem for personal reasons, the interview structure of the SCID enables them to do so. One patient, reluctant to admit she had once been diagnosed with TB, mentions this illness in the SCID, saying only, "They said I strained myself and had some TB, too."

D.D., a 39-year-old Christian woman with high blood pressure and kidney nephritis, articulates a fairly high degree of vulnerability to her health problems in both the SCID and the EI, although in different ways expressive of the narrative properties of the two kinds of interviews. In the SCID she struggles to understand her suffering by asking, "Why me?" She poses this question in terms of her relationship with God, saying "I've been asking the Lord. I've said, 'Are you punishing me?' You know, 'Why am I going through this?' You know." This oneon-one interrogation is in contrast to a more "peopled" exploration of how she deserved less than others to be ill that appears in the EI. Here she poses the same question in the context of her family and community: "You know, you see people getting drugged or you see people just wasting their lives on all kinds of drugs, and I'm not even doing that. Why? Why me?" Later in the interview she returns to this question: "I used to say 'cause my sisters, they drink a lot, why couldn't it be them? Why me?"' In the EI, D.D. also reveals that she feels like a "guinea pig,' after having three kidney biopsies done. The image of the hapless laboratory animal was actually articulated by her husband: "And my husband was telling me that. Maybe you're just a guinea pig to them..." As D.D. recounts the conversation in which he said this, she suggests that the image does capture her feelings of helplessness and bafflement about her illness and the biomedical treatment she has undergone. She does not mention feeling like a guinea pig in the SCID. Aside from the religious/ moral dilemma that her illnesses pose, what D.D. reveals about her illnesses and symptoms in the two interviews is fairly typical: the responses in the EI are more detailed, more "peopled" and more revealing of her social context than in the SCID. In the EI, her response to the interviewer's question about why she had three kidney biopsies, D.D. is quite voluble: "I really don't know. The second time when they did a kidney biopsy they took out three small pieces. They kept saying, 'This is real small, we need some more.' And so they kept on. They did it three times. And to me, if it was real serious, and if it was real bad, they could have contacted me right away for me to go back into the hospital or whatever they're gonna do. But so far there's nothing like that..." Asked, in the SCID, if she was in the hospital for 
kidney problems, D.D. says only, "That, oh, that one was for a, yeah ... to get a biopsy, yeah."

A notable exception to the tendency of participants to be terse and selective in naming their illnesses and listing their symptoms in the SCID and inclusive and descriptive in the EI is the case of K.M., a 35-year-old Traditional male suffering from injuries sustained in an auto accident. He mentions only his neck injury in the EI, while listing several related and unrelated problems in the SCID. Thus, in the SCID, the neck problems were one problem among many, while in the EI, the neck injury loomed very large, giving a more subjective picture of the place in the patient's life this problem occupied. Although there are striking differences in this patient's account of his illness from the SCID to the EI, his discussion of the experience of the injury is unusually rich and nuanced. He describes in both the SCID and the EI how his injuries affected his identity, and speculates at length on the causes. These are expressed both in terms of biomedicine (e.g., "cervical injury") and in "Navajo-centric" terms (e.g., witnessing the death of a child and participating in a ceremony of questionable appropriateness). This patient is unique in several respects. First, he straddles some of the categories constructed in the research design: although he identifies primarily as a believer in Navajo Traditional religion, he has an NAC permit, and describes himself as a "charter member" of the Navajo Episcopal church. He is both a patient and a healer-in-training. And while his contacts with biomedicine have been painful, frustrating and even demeaning, he advocates for more tolerance and understanding between practitioners of traditional healing and those of biomedicine. K.M. stands out because of his articulateness and his ability to adopt multiple viewpoints, characteristics that enabled him to volunteer a great deal of reflective information on his physical and psychological condition in both the SCID and the EI with relatively little probing on the part of the interviewer.

\section{Causality}

Conceptions of illness etiology constitute a domain of cultural assumptions that bear directly on illness experience. Given the more open-ended nature of the EI and its explicit concern with illness etiology, and the SCID's overt goal of determining the existence of symptoms without attending to their causes, we expected the narrative data produced by the EI to include considerably more references to causality. This was not the case: there was no difference in the number of unique cause references per 10,000 transcribed words $(p=0.61)$ between the two interview genres. It is possible that this result is due in part to implicit imposition into the narrative process of the Navajo cultural emphasis on causality in matters relating to health.

This quantitative convergence between the two interviews says little about how causality was discussed in the two interviews, however. When we examined the narrative elaboration of each causal reference, a number of striking differences appeared. The SCID, which seeks to elucidate the presence or absence of a predetermined set of symptoms codified in the DSM, recurrently elicited highly clinical notions of causality that corresponded closely with the 
DSM nosology. In this regard, discussions of illness etiology rarely deviated from the framework of symptoms explored in the SCID, constructing rich yet highly focused accounts. Although causes rooted within specific Navajo religious orientations did emerge, the biomedical notions of causality implicit to the SCID overshadowed them.

In contrast to the SCID's predetermined and focused narrative construction of causality, the EI reflected a comparatively expansive and indeterminate process of causal construal. With its open-ended structure, patients consistently accounted for a wide range of potential causes, rarely settling on a simple causal relationship between a single event or agent and a specific symptom. Patients balanced many different potential causes, alternatively foregrounding and backgrounding the relative significance of various causal attributes throughout the interview. Rather than associating depression, or a simple skin rash, with only one cause-whether it be childhood abuse or contact with poison ivy-we encountered broad fields of explanation that included complementary explanations such as harming an ant as a child, failure to complete a prescribed set of rituals, or a parent's or ancestor's misconduct. In this regard, ethnographic narratives more frequently elicited specifically Navajo notions of illness causality that both highlighted a range of potential causes and intricately enmeshed the individual within a particular cultural environment. Illness etiology was limited to neither a single cause nor a temporal frame demarcated by patients' own experiences.

An important dimension of the EI's openness to causality was its tendency to be more pluralistic. Specifically, the EI reflected a nuanced recognition of the interrelationship between notions of causality and the distinct Navajo religious orientations (Traditional, NAC and Christian). This is captured well in the following brief yet telling exchange between an ethnographic interviewer and a 55-year-old female patient considering the significance of lightning (a prominent source of illness among traditional Navajos) as a potential cause for her problems:

Patient: The lightning struck in front of me.

Ethnographer: Does that bother you sometimes?

Patient: It used to bother me when I wasn't a Christian. They say that it burns on the inside of you.

What is striking about this passage is its depiction of not only the notions of causality associated with specific religious orientations but also the variable significance attributed to events, depending on one's religious orientation. Although lightning was a cause when she was oriented toward Traditional Navajo religion, now that she has converted to Christianity it means little. This passage reflects not only the pluralistic nature of causal construal in the EI, but also its ability to render shifting understandings of causality over time-a theme to which we return below.

The SCID, conversely, primarily structured causal narratives around biomedical themes, regardless of whether reference was made to culturally specific Navajo notions of causality. That is, the nonbiomedical causal explanations that appeared in the SCID were incorporated into narratives in ways corresponding to the DSM's Glossary of Culture-Bound Syndromes. Paralleling the DSM's relegation of culturebound syndromes to a single appendix following the manual's text, which in its 
positioning serves to totalize a vast array of cultural understandings into a single culturally "other" category (Jenkins 1998), the SCID produced narratives consigning a multiplicity of causes associated with specific Navajo religious orientations into a general, nonelaborated category of "Navajo." As opposed to the SCID's production of culturally unelaborated narratives of causality grounded in a generalized distinction between biomedical and Navajo, the EI produced narratives that included biomedical notions of causality as well as a range of potential causes associated with the three distinct Navajo religious orientations.

This reflects an important difference in the narrative processes of the two interview genres with respect to articulations of narrative positionality. In the EI, respondents were frequently situated in such a way as to highlight their awareness of their own positionality. Ethnographic narratives, in this regard, appeared significantly more reflexive in nature. The following conversation with an 18-year-old female patient seeking help for her ailing child illustrates our point well:

Ethnographer: And if I was to ask you this question: What do you think caused it [the meningitis]? I guess, how would you answer that, then?

Patient: $\quad$ Is that in Navajo, traditional? Or, just, uh-

Ethnographer: Either. Both, maybe.

Patient: Both? Yeah. Probably, just the doctors looking at it would probably just be that, she was around someone who must have had it. Must have had it, and gave it to her. They coughed on her, or sneezed on her, or something.

Ethnographer: Yeah. Mm-hmm.

Patient: And that's how she could have caught it. And, in traditional, I would just say the same thing I said with my dad, witchcrafting.

Beyond revealing the relatively young age at which Navajo youth can convey the complexities of Navajo identity, a more general awareness of her situatedness between competing belief systems and ethnomedicines is evident. Questions such as "Shall I explain this in Navajo traditional terms or in terms of biomedical medicine?" rarely appeared in the SCIDs, which produced less reflexive narratives that de-emphasized participants' cultural situatedness and the plurality of cultural worlds within which they were embedded. Whereas positions were largely static and unreflexive in the SCID, they were shifting, pluralistic and reflexive in the EI. Furthermore, as respondents such as the young woman discussed above negotiate between different cultural idioms, their narratives highlight the EIs' ability to capture the various ways in which patients position themselves as they move among distinct cultural and linguistic worlds.

\section{Social Environment}

Essential to the experience of illness and healing are conceptualizations of how individuals (as bodies, persons or spirits) relate to environments (sacred, social or behavioral). This is a point that Gordon (1988) has made regarding biomedicine's implicit structuring of relationships between individuals and the worlds they inhabit, and is equally the case in systems of indigenous healing. Our two interviews create 
different narrative environments that produce different readings of persons in their social environments. On the one hand, the EI tends to construct a narrative environment where an ill person is situated within his or her social world; the illness experience is intensely social, with the ill person seen as an agent operating in an intricate and enmeshed world of interpersonal relationships. On the other hand, the SCID tends to construct a narrative environment where an illness is situated within a person; physical symptoms and debilitating effects ensuing from illnesses are foregrounded, resulting in an understanding of the illness experience at the intrapersonal level. While one is socially external, the other is symptomologically internal. At times, this difference between interview environments produces strikingly different results.

The effect of narrative environment on social environment is most conspicuous in relation to how respondents discussed other people within the two interview formats. If we can conceive of the points at which patients discuss others (friends, family, coworkers) in the interview process as representing nodes through which narratives extend outward into the social world, the EI narratives are clearly far more socially engaged. Through embedding narratives with multiple references to other people, patients situate themselves within the broader realm of society. Making sense of how patients perceive themselves within a dense and interconnected social world thus opens a larger window onto understanding the social nature of illness. This theme is well illustrated by an EI passage from a female patient suffering from headaches:

But if I go like this, when I turn this way or back I can feel it. I had a girlfriend that died of a tumor in her head. She's really young. She was about 22. She used to be one of my students at the dorm, and she's from Hard Rock Mission. She's tall and she had long hair way down to her ankle, and she's really good in the traditional way of life. But she knows how to read, knows how to make sash belts. She used to know how to cook corn with everything, like, you know, yellow corn, you know. She used to make bread with corn, mush with corn, she used to make stew with corn, and that, what do you call that, it looked like tamales, you can make it with a corn.... But she makes the corn, makes it with meat and sheep fat. Then she'll just roll it up and boil it. And everything went with corn.... But anyway, she died in 1984, I think it was. And she used to work at Bashas, cashiers. I guess when she was working there she came down with headaches like all the time. And the headache got so bad where it just put her to bed and she wouldn't eat, she wouldn't drink water, she just laid there, and finally they had to rush her to Flagstaff medical center. That's where she died a couple days later. She was married, she had a little boy. And her sister took her little boy. Her husband has another one. Sometimes I think about her, you know. Because she was sick, [needed] help you know, sort of just bearing that pain. She used to come around and visit me and we would just talk. But she never mentioned her headache. She never talked about it. And like this morning I went to see my mom, she asked me "How's your headache?" I said its still there. 
Compared to the SCID's focus on specific symptoms occurring over defined periods of time, this woman's narrative was a thoroughly comparative discussion conveyed through a series of connections between her experiences and those of her friend. Her narrative, in other words, was constructed principally through another person's experiences. In this regard, she highlights the socially engaged and peopled nature of EI narratives.

Although representing the degree to which the SCID produces less peopled narratives is problematic, quantitative measures do well to substantiate our point. On average, there were 3.86 fewer unique references to other people per 10,000 transcribed words $(p=0.002)$ in the SCID compared to the EI. Additionally, EIs were far denser in the number of times each person was mentioned. References to social support and social conflict reflected similar patterns, with the SCID averaging 2.83 fewer unique support statements $(p<0.001)$ and 0.70 fewer unique conflict statements $(p=0.008)$ per 10,000 transcribed words relative to the EI. Furthermore, ethnographic support and conflict statements tended to be detailed and peopled, whereas SCID statements tended to be general and lack elaboration.

The SCID's emphasis on associating symptoms and effects to specific illnesses also served to fragment the patient's illness narrative into a set of constituent parts. It was then the clinician's task to bring these constituent parts together in the diagnostic process. Conversely, the EI tended to portray the illness experience as a unified whole, with a pastiche of symptoms and effects narrated into a larger story. As a result, patient symptom narratives in the EI were difficult to pull apart and ascribe to particular illnesses if multiple illnesses were discussed in the interview. The analytic nature of the SCID, however, did not intrinsically limit patient narratives. In fact, it was frequently beneficial and led to the successful elucidation of various problems contributing to the patient's condition. For these patients, it provided a valuable means of comprehending the larger illness experience, recognizing temporal trends in illness and formulating treatment regimes that were not readily apparent from the EI. For other patients, however, this analytic process erected artificial boundaries in an illness experience better perceived as a unified whole. In these cases, because the patient found difficulty in conforming to the boundaries defined by the SCID, the interview unfolded as a struggle between interviewer and interviewee in the assignment of specific symptoms to specific illnesses.

While the above discussion shows a highly consistent pattern of social embeddedness within the EI, we are by no means defining the SCID as socially disengaged. An important implication of the SCID's focus on symptoms and the resultant schematization of illness narratives was its ability repeatedly to disclose not only illnesses but also significant life events undetected by the EI. These events often contained highly sensitive subject matter that the patient appeared uncomfortable discussing in the EI. We suggest that this may be because the social embeddedness of the EI, and the correlative implications of social stigma, led participants to be apprehensive about discussing sensitive matters such as rape, substance abuse and spousal abuse, and thus to a certain amount of conscious or unconscious self-censorship. Conversely, the narrative environment constructed by the SCID encouraged patients to focus on the manifestations of illness, providing 
some distance from the social world and, in turn, lessening concern about social stigma. Rather than describing this difference in terms of relative strength and weakness, it is more precise to say that the two interviews have complementary styles of depicting people, their illnesses and the social worlds they inhabit, and complementary understandings of how a given person or problem relates to a broader set of social relations.

\section{Temporality}

The EI and SCID employ differing temporal frameworks that imposed constraints on our narratives of life events and experiences of illness and therapy. The structure of the SCID entrains a clear chronologization of illness experience, with repeated attempts to locate and frame symptoms within particular periods of time (e.g., in the past month or over a two-week period). The resultant interview narrative closely followed the interview structure, with a set of isolated experiences occurring at various intervals construed into a precise linear temporality. The interview of a female patient, R.B., suffering from breast cancer was indicative of this phenomenon:

Psychiatrist: Well, we will, move onto the next section, then, I'll take this back (flipping pages), now I'm going to ask you some more questions about your mood, um, in the last four weeks, you know, since your daughter's birthday, has there been a period of time when you were feeling depressed, down, lonely, or lonesome most of the day, nearly every day?

Patient: Oh, yeah. Mm-hmm. I was burned out, from going to school, and, sometimes I think back, you know, to why, I'm running into a lot of health problems, and,

Psychiatrist: Mm-hmm.

Patient: What it would be like, you know, if my ex-husband and I were still together, you know.

Psychiatrist: Yeah.

Patient: $\quad$ Sometimes my little boy will ask where his father is, and...

Psychiatrist: Yeah.

Patient: It kind of puts [gets] me down.

Psychiatrist: This is something that you've felt in the last four weeks, too?

Patient: Mm-hmm. Yeah. Three weeks ago I was, I don't know, it just, I just got myself sick, because, um, um, our research papers were due, term papers, and all that, I had to...

Psychiatrist: Yeah.

Patient: How am I going to get to Flagstaff and, so I was just burned out and, I had a, a headache from the back of my head, here?

Psychiatrist: How long did that kind of low mood last?

Patient: $\quad$ Oh, it took...

Psychiatrist: As long as two weeks? 
Patient: $\quad$ About two or three or four weeks sometimes.

Psychiatrist: Oh, in the last month has it lasted that long?

Patient: Uh-huh. Last month, uh-huh. And, for a whole week, I was just in bed, cause um...

As this patient's narrative reflects, the SCID typically succeeded in establishing particular time frames of given symptoms - the age at onset, the number of weeks and months it persisted, etc.- - and imposing this temporal structure onto patient narratives. Relative to the EI, where patients provided their own temporal frame for symptoms, SCID narratives often emerged as linear framings of people's illness experiences. It is also evident in this interview that, in service of the diagnostic goal, the interviewer left several narrative threads unfollowed, including burnout, other health problems, doubt about her relation with her ex-husband and her child's relation to his father.

The EI, however, tends to generate more of a sense of the duration of participants' illnesses that places their experience into the temporal frame of a narration organized not around abstract chronological markers but, rather, around a series of life events constituting transitional nodes within a larger plot. Although narrators frequently (and often unexpectedly) jumped around in time, stepping effortlessly from one life experience to another, these temporally disjointed narratives nonetheless wove into a larger story of their lives and their illnesses. Just as the EI tended to portray the ill person within a social world, so too did it position the speaker within an unfolding story. For instance, rather than situating a symptom in relation to a particular year of onset, patients in the EI articulated a narrative frame in which symptoms were described in relation to specific life events, transitions and experiences-such as entering the military, enrolling in boarding schools, attending church revivals or having significant encounters and conversations. The same patient whose SCID we just quoted discussed her cancer in the EI as follows:

I had surgery on this finger here. And the doctor told me I was catching arthritis cancer or tumor, arthritis tumor. And I noticed I'm getting those on my big toe, on my right big toe. I'm also getting that too. It's uh, my nail, my toenail, it's getting deformed. He said if you're nails are getting deformed, that means you are getting that arthritis tumor. I think it's kind of going way back to the past,; my aunt never gave us milk. We lived way out, she camped you know in the Hogan, and we never had milk and, uh, I remember she used to give us tea and coffee. And that's all we lived on. And in our younger days we never got the right kind of food that we were supposed to be eating. And never drank the right, like milk. I remember once, I think it was just once, we had goat milk. And we'd boil some goat milk and we'd put that, uh, blue corn powder stuff and mix it like chocolate. That's how we drank it. And then, uh, I know they used to be receiving Carnation milk. But they give that milk to the small goats instead of giving it to us. We needed milk more than the goats did. And then the boarding school, we never did get fresh milk, we used to drink Carnation milk, I never did like it. I remember it in the morning, that 
Carnation milk, they just poured in there in the glass for you and they forced you to drink it. I never did like it. Even our bowl of cereal, they said just pour a bunch of milk in there and mix it and then you could eat it. They have that Carnation milk that tastes real strong stuff. I never did like it.

Although discussing a different illness experience, we nonetheless see how the narration of her present cancer carried the speaker from her therapeutic encounter with a physician to her childhood with her aunt and, finally, onto her adolescence in boarding schools. Narratives such as this have temporal significance in their ability to simultaneously render the past and present into a unified but interpretively malleable story that points toward an indeterminate future and leaves their options open and hope for a future cure in place.

Further examples of how the interview genres diverge with regard to temporality appear in the manner in which EI narratives trace a frequently drawn-out healthseeking career-an often prolonged search for diagnosis, an encounter with numerous healers and a persistent hope for recovery. Note, for instance, the following 43-year-old female patient's story regarding her treatment history. Although it appears disjointed, it is nonetheless a narrative focused on, and leading up to, her current healing experiences.

I, then I pulled a muscle on my neck, I wound up wearing one of those, uh, neck braces? And uh, all he [the doctor] gave me was muscle relaxers and pain killers, which I can't take because my stomach is too, ah, sensitive to, uh, hard, you know, White Man's medicine. Like it's the chemicals in it. It just develops, uh, an inflammation in my stomach so I can't take anything. And herbal-I believe herbal medicine, it's worked for many people, and, it works for me.

Turning to a more recent experience of whiplash, she explains,

I've been seeing a chiropractor every week, and it doesn't seem like, to do any-it's not helping out at all, and I knew there was something else that I had to do, and so I was searching for a medicine man....

After also mentioning an acupuncturist she visited and punctuating the conversation with long narratives of other illnesses and treatments she had experienced throughout her life, the patient finally arrives at her present healer:

I knew I had to see somebody out here, because the Navajo people are very spiritual, and they uh, their medicines are strong, so I thought, somebody has to help me, because I mean, it has-it's got to be here. And, uh, it was a big relief for me when I finally went to uh, see [the healer] for help, and uh, he knew exactly where, where, where uh, the injuries were, and which parts to uh, to work on, and um, well, since I've gone over, like three or four times now?

As opposed to the rich EI narrative, this patient provided very little detail of her treatment history in the SCID, simply explaining that she had suffered for 
some time and eventually sought the assistance of the healer she was currently consulting.

Our point here is not that the SCID produced a temporally impoverished account of patients' experiences. We are arguing, instead, that both interviews, while rich, constrained patients' narratives differently. In this regard, the SCID generated a far more segmented and temporally schematic image of a patient's health-seeking career. Although providing a limited understanding of how various ideas of etiology, speculations about diagnosis, and experiences of treatment were related to one another, the SCID was rich in other ways. For instance, it was better able to discern times of onset and duration of symptoms. Additionally, as mentioned earlier, the SCID's linear framing of time brought up significant events that did not, and would not have otherwise, emerged during the EI. Although the SCID seems ill formatted for handling multiple problems_-and placing them within a meaningful time frame for patients - it was able to more fully explore dimensions of a problem that would not have emerged if not for its strict linear framing. Consequently, while the SCID drew on temporal frameworks not particularly relevant or meaningful to patients, it did provide frameworks of more utility for purposes of diagnosis. In sum, the SCID's emphasis on pathology produces a narrativity focused on the intensity of episodes, and not on how they were connected to one another. In this regard, the narrativity of the SCID appeared telegraphic, broken up by repeated probing as it steadily intensified its focus on particular events. In contrast, the EI produced heavily emplotted and temporally textured illness stories framed within patients' overarching life stories.

\section{Identity/Self}

In both interviews, participants' comments pertaining to self had to do primarily with relations, social obligations, hobbies, employment, and personality qualities. For example, it was often the case that an interviewee defined him- or herself as a mother or father, designating this in various ways such as, "I am my son's mother." Other self-statements involved likes and dislikes, such as, "I like to weave" or "I do not like public places." Comments pertaining to identity in a broader sense predominantly focused on Navajo cultural identity and on religious identity that contrasted Traditional, NAC and Christian allegiances. When participants talk about these identities, the discussions take the form of relational or comparative narratives that show inclusion within a social group, distinguish themselves from others, or provide evaluations of other people.

Given the different purposes of the two interviews, as well as the fact that questions and probes specifically addressing issues of self and identity were common in the EI, it is not surprising that the EI produced longer, more detailed discussions of these topics. Specifically, the EI averaged 2.11 more unique identity statements $(p=0.002)$ and 1.25 more references to character traits $(p=0.03)$ per 10,000 transcribed words. Of considerably more interest, however, is the manner in which self and identity statements that do appear can be compared across the genres. 
First, most self and identity statements found in the SCID appear in the first few pages of the interview. This is because the early portion of the interview includes conversation that establishes rapport between the interviewer and the interviewee. Whereas the content of these initial moments is typically pursued and elaborated by the ethnographic interviewers, it holds less substantive importance in the SCID, where the primary importance of interviewee self-understanding is to reveal or point to symptoms or diagnostic criteria. Self statements in the SCID work deductively, helping the clinically trained interviewer to infer the presence of psychiatric illness. In contrast, self statements in the EI work inductively, so that the anthropologically trained interviewer can build a greater understanding of the interviewee's subjectivity.

Second, differences in self and identity discourse in the two interviews corresponded to the observation that ritual healing and identity politics on the Navajo reservation are deeply intertwined and can be observed at three levels: (1) in the articulation of Navajo identity vis-à-vis Anglo-American society; (2) in the interaction and negotiation of the three forms of ritual healing present on the reservation and (3) on the individual level of patients' experiences (Csordas 2002). SCIDs often engaged identity on the first level, with comparison of Navajo and biomedical forms of healing articulated as expressions of Navajo identity vis-à-vis Anglo-American society. The following passage from an interview with a 44-yearold female patient, for instance, describes this through the idiom of two distinct healing systems:

And then they go back [to the doctors], and then the doctors probably think that, you know, um, there was, that whatever they did was the cure, but not, not realizing that the pa-, especially with Navajo, that they have gone a, a different route, getting, getting, going through the healing process.

The recurrent therapeutic process this patient narrates was, as we have described, a movement between two specific styles of healing: biomedical and Navajo. On the other hand, the EI typically engaged identity on the second level, tending toward a pluralistic discourse with comparisons among the three ritual healing systems on the Navajo reservation. The same patient as above, now in her EI, provides the following example:

They need, they should respect each other, whatever religion they have, even though they may disagree. And not criticize each other. It's their religion, whatever they want to do with it, you know, just leave it alone. Just go about my way and mine, you know, that's how to be. You always have to say you Christians are like that, and NAC is good, and then you know, they always have something, not pleasant to say about each other.... And then that, that sort of thing, like you know, in the prayers, included in the prayers, see a lot of times, when they pray, they, they blow it out of proportion, I think.

Here the relationship between Navajo and Anglo identity is not at issue, and the narrative worked at the level of the interaction and negotiation of identities based on the multiple systems of healing present on the Navajo reservation. 
Within the SCID, therefore, Navajo identity was repeatedly constructed in relation to an outsiderly Anglo identity, reflecting a tendency toward polarity between generalized ethnic identities that do not attend to the multiple internal variations of Navajo identity. Narratives elicited by the EI tended toward articulating a notably different conceptual connection between healing and identity, but it is not simply a matter of participants being more specific in the EI concerning the intricacies of identity. Insofar as identity emerges through establishing difference, identity statements are employed strategically to position speakers within multiple fields of cultural difference. The different ways in which identity is discussed in the two interviews thus represents different intentions-or strategiesbeing employed by the speaker. The SCID, on the one hand, reflected a concern with establishing a general Navajo identity, positioning the speaker within a broader North American set of identity markers. The EI, on the other hand, established a specific Navajo identity in the context of the multiple lines of religious differentiation extant on the reservation today. Where one points outward in the process of identity production, the other points inward-toward the intracultural variations among Navajo. The presence of this pattern is a vivid instance of variations in narrative positionality and self-presentation in the interview process.

Religious affiliation played a major role in interviewee self-understanding within the personal narratives found in both interviews, but was especially evident with two types of participant. First were those Navajo Christians who had converted from adherence to Traditional Navajo religion. Steeped in Christian discourse and imagery, their narratives often involved describing themselves as close to God, children of God and explicitly Christian in identity. Narratives in both the SCID and the EI often took the form of "testimony," a central genre in Christian discourse in which the experience of God's power is celebrated both to affirm the speaker's faith and to evangelize the unbeliever. Of particular interest was the way these testimonials became incorporated into the context of illness experience such that metaphors of suffering, death and/or resurrection of the interviewee were understood in relation to the Christian Passion. F.H., an older Navajo Christian woman, exemplified this use of testimony in both interviews when describing her experience with severe pneumonia. While in the emergency room in the throes of death, she had visions of traveling below the ground in an elevator that she associated with the biblical story of Jesus entering Hell after his crucifixion. She maintained this biblical narrative by interpreting her resuscitation through the use of heart stimulators as analogous to Jesus's resurrection. The second group consists of those Traditional and NAC participants whom we initially interviewed as healers and later included as patients when they themselves underwent ritual healing. These healer-patients often included in their narratives highly elaborated discourses on Traditional and NAC beliefs and practices characterized by a distinctly pedagogical tone. M.K., an interviewee who was both a patient and a healer, often addressed his belief in peyote and Traditional ways in such a manner that discussions in both interviews would often lead to narratives confirming his beliefs through an understanding of the logistics of various ceremonies. In these narratives he would state how he was trying to be what he always wanted to be-a Traditional, reverential Navajo who benefits other people. 
Whereas Christian converts and Traditional or NAC healer-patients both produced identity-laden discourses, they did so from different standpoints. Christians made a declaration of faith with evangelistic overtones, while healer-patients presented an exposition of the breadth and depth of Traditional or NAC religion. Christian converts tended to embrace biomedicine relatively more readily as part of the cultural complex of modern life, while healer-patients tended to express an implicit underlying tension between themselves and biomedical healers. Voluntary production of such extended discourses containing information on cultural assumptions, personal identity and religious knowledge appeared more likely to serve the goals of the EI and to circumvent those of the SCID. In the Christian convert case, this was because testimony was often tangential to the diagnostic goal; in the healerpatient case, it was often because the clinically trained SCID interviewer was recognized as a representative of the competing medical profession.

\section{Radical Convergence and Divergence across Interviews}

In comparing the narrative properties of the EI and SCID, our attention was drawn to a group of participants for whom the two interviews were substantively almost identical, and another group for whom the interviews were so radically different that the participant appeared to be a completely different person in one interview compared to the other.

In the first case, we encountered several instances in which a patient's EI and SCID, either in their entirety or in part, were remarkably similar. Take, for example, the following patient's discussion of his father's death. First, in the SCID, he explains:

When the accident happened, we were going on a slide, and then everything that hap-, used to happen, in that time, kind of just stopped right there. And a whole different life came from that one. And then my dad died, and everything that happened there, it just stopped, you know? Seems like, going on this, review line, a new direction. Everything's changed again.

Second, when asked how his father's death affected him in the EI:

Well, it's kind of, everything just stopped. This life that I was living, it just stopped. And I took a different direction, a new one, and it comes, they're trying to get used to it. Everything's changed, nothing's the same.

When we consider that the two interviews were administered by different research teams, were made up of dissimilar sets of questions and were separated by an extended period of time, the degree to which these utterances are similar is striking.

In general, in this set of radically convergent interviews the interviewee dictated the agenda, overriding the interviewer's discursive control and transcending the narrative constraints imposed by the differing structures and intended purposes of the SCID and EI. Participants most likely to have qualitatively convergent interviews tended to have one or more of the following traits: (1) be an evangelical 
of pentecostal Christian; (2) have experienced a particularly powerful life event; (3) have a dominant personality; (4) be male and (5) be elderly. Having a greater number of these traits indicated a higher likelihood of qualitative concordance, although the latter two traits in themselves were not sufficient to produce this effect.

Christianity tended to be the most powerful factor in determining convergence of content and style across interview contexts. Although the symptoms and illnesses varied among this group of patients as much as among the others, and regardless of their particular illness experience, religious meanings, concepts and narrative style were very much alike among Christians. Like Traditional and NAC patients, Christian patients embedded their symptoms in their own distinct religious etiology and treatment. However, unlike Traditional and NAC patients, many Christian patients' discussions of these phenomena adhered to the same narratives, with the same facts told in the same manner across interviews. Many of these interviews revolved around the patients' testimonies of salvation through Christ and miracles of healing. The opportunity to witness or testify and the possibility of proselytizing took precedence: one participant expressed explicit awareness of addressing people who may read the eventually published research findings. Particularly within evangelical and Pentecostal streams of Navajo Christianity, witnessing represents a profound re-enactment of one's conversion and a confirmation of one's Christian identity, as indicated above. One is compelled to witness. Christian witnessing is a narrative genre that, for the patient, supersedes other narrative constraints as the stories take on a rehearsed quality, indicating how often these scripts may be told and how central they are to the narrators.

Second, a powerful life event is often associated with qualitatively convergent interviews. In this regard, certain life experiences emerged as so central and so intense for respondents as to overwhelm, and transcend, the narrative constraints imposed by the interview structure. In particular, the death of a loved one has implications for the illness process on many levels, not only with respect to the pathogenic response to bereavement recognized in the Western biomedical perspective, but also with respect to the Traditional Navajo notion that illness may be caused by the ghost of a close relative. The narratives often involved supernatural elements (e.g., miracles for Christian patients and encounters with nonhuman spirits for Traditional or NAC patients). Participants often became extremely involved in such narratives, occasionally crying at points. Interviewers would often stop asking questions for a period of time and take a break or even suspend the interview until a later visit. In these instances, narrative convergence was a product of the compelling nature of the life event and the manner in which it had become intrinsic to the interviewee's selfhood.

Third, a dominant personality was a factor in many qualitatively convergent interviews. These patients tended not to pay attention to the interviewers' attempts to "get back on track" but, instead, talked about what they wanted. When interacting with Christianity, this dominant personality produced an interactive situation in which the interviewee was able to assert him- or herself over the interviewer's attempts to adhere to the interview structure. Fourth, men tended more than woman to dominate the interview and be less adherent to the structures of the interviews. This may have been due to the men's having a greater sense of authority 
and assertion over the interviewers. However, this was not always the case, as there were several instances of women, particularly Christian ones, who asserted themselves as much as the men did. Fifth, our few elderly tended to have qualitatively convergent interviews, but for the most part their interviews did not resemble either the typical EI or the typical SCID. They tended to be monocultural and have little experience of contact with "Anglos." Thus, they appeared to be unfamiliar with the nature of an interview or may not have known the "correct" way to respond to interview questions. Also, many of these interviews were conducted in Navajo with the assistance of an indigenous interpreter whose deference to the elderly participant further altered the nature of discourse.

With respect to those instances where we observed radical differences across interviews, not only did such a difference occur with respect to narrative content of events and illnesses, but interviewees' demeanors and styles of self-presentation also modulated dramatically across interviews-from despondency to hostility, from engagement to combativeness. In one case, the patient became so unexpectedly belligerent and uncooperative in the SCID that analysis, let alone diagnosis, was impossible. For a handful of similar cases, the experiences, themes and episodes discussed diverged to the point that the contours of the patient's life seemed hardly to overlap across interviews. For the most part, our examination of factors accounting for radical divergence led us to regard this set of interviews as an exception that proves the rule: on the one hand, structural differences between the interviews resulted in less divergence than might be anticipated; on the other hand, factors extrinsic to the interview format highlight the methodological importance of pragmatic issues in generating divergence.

On the structural side, we observed for this group of participants that differences between the interviews had a pronounced effect on narrative presentation. First, in the more meaning-oriented EI, these participants were much more likely to present a self in relation to the surrounding social world, while in the more pathology-focused SCID, the self was often presented as a series of specific intrapersonal conflicts. Second, the EI tended to focus on both the past and present and their bearing on the future, while in the SCID there was an initial focus on the present, with a subsequent move backward in time. With the SCID, it was quite common that, if an interviewee detailed no current pathology, the clinically trained interviewer would initiate a life history survey in a search for signs of mental illness. If such signs were discovered, they would often take up a significant portion of the interview. In this regard, it seemed that the psychiatrist searched for a specific kind of subject matter, so as to find moments in the narrative that were prime for reimposition of the SCID structure. While this method often led to mutual confusion between the interviewer and the interviewee, it was sometimes effective, leading to revelations concerning extended periods of mental illness not discovered in the EI. This was the case with HR, a middle-aged woman who, on detailing no current pathology, was probed by the psychiatrist until she revealed a visit to a psychiatric hospital 15 years earlier. This visit became the focus of the SCID, rendering it vastly different from the EI in terms of focus and scope. This pattern typically led to substantive divergence between the interviews in participants (1) who had no current pathology but (2) whose life history in the SCID revealed a bout with mental illness that then (3) took 
up the greatest amount of interview time and (4) under the clinical interviewer's probing, dealt more strongly in Western conceptions of illness experience.

The EI, on the other hand, kept much of the discussion in the present. Most of the questions situated the interviewee in a cultural world mediated by an intricate web of social relations that have a bearing on individual interpretation and decision making. Issues of causation, for instance, were often brought out with special attention to the patient's own understanding of causality, whether through a direct personal interpretation or through those given by family, friends and/or other associates in the larger social network. If a cause-or, more precisely, causes (because it is rare that one factor is seen as the single cause)-is articulated, the more open-ended nature of ethnographic interviewing leads to further questions for elaboration. This questioning just as often follows the lead of the interviewee, who may wish to pursue multiple narratives, as it does the ethnographic interviewer's protocol. Multiple narratives and interviewee interpretation are powerful because the interviewer must dynamically engage the participant so as to inductively grasp those points of narrative significance that are of greatest importance not only to the larger goals of the interview, but to the interviewees themselves. Only when a cause relates to the kind of conflicts that the SCID defines as illness-inducing do interview similarities begin to appear.

On the pragmatic side, we found that greater-than-expected divergence could be accounted for by what we call the pretext, subtext and context of the interviews. By pretext we mean the pre-existing relationships interviewees may have had with the interview team. While the SCID interviewer typically met the participant only once, usually the lead ethnographic interviewer was present for a healing ceremony or other such event giving him or her firsthand knowledge of the event procedure and of those present during the event. This oftentimes guided the open-ended questioning, for the presence of others was indicative of the particular social relations of the interviewee. In comparison to the EI, there were only a few examples of the effect of pretext in the SCID. In one example the psychiatrist and interviewee had a previous discussion on the same issues to be addressed in the taped SCID. This "off-the-record" information led to a confusing, disjointed SCID where the patient seemed to be cueing the psychiatrist with "You know what I mean" and "That's a whole "nother story" in order to move on and finish the interview in short order.

Of even greater importance were pre-existing relationships between the interviewee and the interpreter. These relationships were of three kinds: a relationship implicit in the fact that both interpreter and participant were Navajo, a closer relationship in cases where the participant was a friend or relative of the NHP interpreter, and the even more intimate relationship in cases where a friend or relative of the participant substituted for the interpreter who was a regular member of our research team. It was when the latter condition occurred in one of the two interviews that divergent content was most often generated. This is due to the fact that the interpreters asked interview questions filtered through their own preconceptions of both interviewer and interviewee, then further filtered their rendering of the responses through those preconceptions. As a consequence, the relationship that either the interviewer or the interviewee has with the interpreter worked to limit or 
expand the topics chosen for discussion in the open-ended EI. This effect of pretext could also be discerned in some SCIDs, however. In the case of M.W., the interpreter had also been present for all of the EIs, the last of which was completed less than 2 months before the SCID. His intimate knowledge of M.W.'s life and problems led him often to make statements to her such as, "All this you already told us" and "So it will be repeating the same questions." He would also, from time to time, add his own commentary to his translation of her response.

Our notion of subtext pertains to the presence of hidden agendas or goals of participants that affect the course of the interview and the degree of elaboration of particular topics. The subtext can be determined by participant perceptions of the interview team and, again, by pre-existing relationships that create a reticence to engage or elaborate on a topic: Navajo participants were more comfortable disclosing intimate information to Anglo strangers who they were unlikely to encounter in the future than to Navajo relatives who could, in principle, think worse of them or even use the information against them. In some instances excessively cautious responses can obscure information that has a significant relationship to issues of health and treatment. For example, in one case a female participant went through all three installments of the EI without once mentioning spousal abuse that she revealed without hesitation in the SCID. We determined that this was less likely an effect of the SCID's structure of direct questioning than an effect of the interpreter in the EI being a relative of hers, so that the interviewee did not volunteer this information because of concerns about embarrassment, or confidentiality, or both. Given that in this instance the SCID was conducted in a one-on-one clinical setting, and that the interviewee had past experience with Western mental health programs, she was much more willing to volunteer this important information in the SCID, thus presenting a very different self. We must also acknowledge a sense in which it can be said that the professional interviewer brings a subtext to the interview as speech event. From the standpoint of the interviewee and, to a lesser extent, the indigenous interpreter, this subtext involves the professional and individual assumptions with which the psychiatrist or anthropologist operates. These assumptions may lead to the breaking of narrative flow in either type of interview: the clinical interviewer may identify a narrative element as a symptom and attempt to turn the conversation in a direction to pursue its relevance, while the ethnographer may pick up a narrative element that is of apparent interest but, for the interviewee, is only a step toward making a different point.

Context is the final factor we found to be relevant to divergence between interviews. Specifically, the location where the interview takes place has much to do with what kinds of responses are given, because it taps into issues of comfort, disclosure, and constraint. The example just given, in which a woman mentioned spousal abuse only in the SCID, had to do in part with the presence of a relative during the EI, but also with her sense of what is appropriate to say in the home setting in contrast to the clinical setting. A second contextual feature is that significant events can intervene to shape the narrative focus of the interviews. For example, L.W. is a middle-aged Christian patient who participated in EIs that spanned 5 months, then 5 months after her last EI session participated in an SCID. Some time prior to L.W.'s SCID, her daughter died. This event eclipsed the major 
illnesses discussed in the EI, one of which was a brain tumor. The result was interviews as if from two people-one suffering from a brain tumor and consequent depression, the other suffering from grief due to bereavement. A final contextual factor is that the NHP EI takes place in several sittings conducted over a period of time. This leads most importantly to a rapport between interviewer and interviewee-not a pre-existing relationship, but a developing relationship. Over time there is a greater tendency for participants to report things that, at the first visit, might not have been introduced. Moreover, the interviewer's increasing familiarity with the participant, including the possibility of reviewing previous interview transcripts, allows for the development of more significant questions to ask at the next interview. Notions of trust and intimacy often became expressed by the interviewees themselves, who at times made it a special point to tell the interviewer that the interview was therapeutic or cathartic. The trust inherent in rapport is important when considering the two interviews comparatively: it was sometimes the case that the interviewee did not trust biomedicine and hence was hesitant to reveal information to the clinician interviewer, while, as we have seen in other cases, the interviewee was more comfortable talking to a clinician about certain issues.

Finally, the presence of individuals in addition to the interviewee and interviewers was a critical contextual feature. In the case of M.S., a partially amnesic young man recovering from a self-inflicted gunshot wound to the head, his pastor attended all the interviews and often took control of the discourse, either by coaxing M.S. to respond in a particular manner or by responding herself to the questions asked by the interviewers. Her presence allowed her to play a significant role in the construction of a definitive and distinctly Christian account of M.S.'s recovery experience, both to shape his own understanding and so that the interviewer might be struck spiritually by a remarkable narrative of a young boy's recovery through Christ. The grandson of Traditional healer and patient R.H. was present at his interviews, during which R.H. often took on a pedagogical tone, linking his illness experience to Navajo religious understandings. R.H. thus not only was addressing the interviewer, but was also negotiating his relationship to both the interviewer and his grandson, tacking back and forth between the roles of respondent and grandfather.

Although instances of narrative convergence and divergence appear to be diametrically opposed, they have similar implications concerning discursive control in the interview process across interview types. In cases of convergence, despite the interviewer's attempt to reign in the participant's narrative, the latter undermines structurally specific narrative constraints in the retelling of dramatic events or in the process of articulating an alternative narrativity. With this failure of discursive control, notably similar narratives emerge within each interview context. In the cases of divergence, we find a similar inability of the interviewer to control discourse. Issues of pretext, subtext and context shift narrative content and selfpresentation beyond what might be expected based on structural differences between the interviews. 


\section{Conclusion: Methodology as Applied Epistemology}

To observe that a psychiatric diagnostic interview and an ethnographic interview are different is of no methodological interest in itself. To demonstrate how they are different in their narrative properties, to show in what respects they are redundant and in what respects they are complementary, and to do so not in the abstract but in the context of a study actually carried out in the field, contributes to understanding how knowledge is generated in the interview process. The NHP has provided us with the unique opportunity to undertake a comparative analysis of two strikingly different interview genres. Beginning from the insights of Mishler and Briggs, we have analyzed a set of clinical and ethnographic research interviews administered to a group of Navajo patients in order to better understand interviews as speech events that produce narratives jointly constructed by interviewers and respondents. We have examined the narrative constraints of the SCID and EI through a consideration of five substantive themes and the anomalous instances of radical divergence and convergence between interviews with the same participant. Our comparison was concerned less with what one interview is lacking compared to the other than with how common themes found in both interviews are discussed differently.

The narrative variances we have described raise larger questions concerning the relationship between narrative and illness experience. As Byron Good (1994:139) argues:

Narratives not only report and recount experiences or events ... they also project our activities and experiences into the future, organizing our desires and strategies teleologically, directing them toward imagined ends or forms of experience which our lives or particular activities are intended to fulfill. Lived experience and social activities thus have a complex relationship to the stories that recount them.

In this regard, narrating one's illness experience is deeply entwined with illness itself. Just as understandings of the nature of illness and decisions about diagnosis and treatment are part of patients' health-seeking career, so too are patients' multiple retellings of the story of their illness. Illness narratives not only communicate patients' understanding and evaluation of their illness, but also potentially affect its course. The often-competing constructions of illness, causality, social environment, temporality, identity and treatment we have observed within each pair of interviews represent potentially consequential alternative modes of structuring experience.

A finding that does not precisely fit into the other categories we have discussed emphasizes this conclusion. Many interviewees mentioned experiencing feelings of catharsis and relief at being able to talk about their problems. This suggests the existence under some circumstances of a therapeutic least common denominator among talking to a personal confidant, to a counselor/therapist, or to a research interviewer. Yet we observed this effect only as a result of the EI. Perhaps this is because the EI allows development of greater rapport and involvement between interviewer and interviewee. Yet the relatively greater focus of the EI on the person rather than the disease does not mean either that the SCID excluded experientially 
relevant material or that the SCID's focus on illness and symptom were not experientially relevant: recall our epigraph in which a participant expressed appreciation for the way the SCID stimulated her thinking about her situation. We repeat our commitment, from the standpoint of our work in the NHP, to viewing the SCID and EI as richly complementary. Our intent has been to demonstrate that, from a methodological perspective, by better understanding the narrative constraints and potentials of different interviews in practice, we are thus better able to evaluate the types of data produced and their contribution to the interpretive process.

Acknowledgments The Navajo Healing Project was funded by NIMH Grant RO1 MH50394, "Ethnography of Therapeutic Process in Navajo Healing," Thomas J. Csordas, Principal Investigator. The project was carried out under Navajo Nation Cultural Resources Investigation Permit C9708-E and with the endorsement of 5 Community Health Advisory Boards in regions of the Navajo Nation in which the research was conducted. The following individuals made significant contributions to the Navajo Healing Project: Janis Jenkins, PhD, Jerrold Levy, PhD, Beulah Allen, MD, Mitzie Begay, ASW, Michael Storck, MD, Milton Strauss, PhD, Donald Lewis-Kraitsik, MD, Stephanie Lewis-Kraitsik, MA, Theresa CahnTober, PhD, Lusita Johnson, Martha Austin, BA, Ray Begaye, Helen Curley, Deborah Diswood, Mary Diswood, David Begay, PhD, Vimal Bhatnagar, MA, Victoria Bydone, BA, Christopher Dole, PhD, John Garrity, PhD, Meredith Holmes, MA, Wilson Howard, Elizabeth Ihler, MA, Nancy Lawrence, BA, Elizabeth Lewton, PhD, Nancy Maryboy, PhD, Derek Milne, MA, Alyse Neundorf, PhD, Micah Parzen, PhD, JD, Ann Perusek, BA, Cindy Retzer, BA, Denise Saint Arnault, PhD, RN, Matthew Strickland, MA, Allen Tran, MA, Thomas Walker, Jr, Diana Wilson, PhD, Alfred W. Yazzie, Franklin Freeland, EdD, and Emeline Otey, PhD.

Open Access This article is distributed under the terms of the Creative Commons Attribution Noncommercial License which permits any noncommercial use, distribution, and reproduction in any medium, provided the original author(s) and source are credited.

\section{References}

Babbie, E.

1992 The Practice of Social Research. 4th Edition. Belmont, CA: Wadsworth.

Bernard, H.R.

1988 Research Methods in Cultural Anthropology. Newbury Park, CA: Sage.

Briggs, C.L.

1986 Learning How to Ask: A Sociolinguistic Appraisal of the Role of the Interview in Social Science Research. Cambridge: Cambridge University Press.

Csordas, T.J.

2000 The Navajo Healing Project. Medical Anthropology Quarterly (Special Issue) 14(4).

2002 Body/Meaning/Healing. New York: Palgrave

Csordas, T.J., M. Storck, and M. Strauss

2008 Diagnosis and Distress in Navajo Healing. Journal of Nervous and Mental Disease 196(8): 585-596.

Dole, C., and T.J. Csordas

2003 Trials of Navajo Youth: Identity, Healing, and the Struggle for Maturity. Ethos 31(3): 357-384.

Denzin, N.K., and Y.S. Lincoln, eds.

1994 Handbook of Qualitative Research. Thousand Oaks, CA: Sage.

Elliott, R.

1984 A Discovery-Oriented Approach to Significant Change Events in Psychotherapy: Interpersonal Process Recall and Comprehensive Process Analysis. In Patterns of Change. L.N. Rice and L. Greenberg, eds. New York: Guilford. 
Elliott, R.

1986 Interpersonal Process Recall (IPR) for Psychotherapy Process Research. In Handbook of Psychotherapy Process Research. L. Greenberg and W. Pinsof, eds., pp. 503-527. New York: Guilford.

Fontanna, A., and J.H. Frey

1994 Interviewing: The Art of Science. In Handbook of Qualitative Research. N.K. Denzin and Y.S. Lincoln, eds., pp. 361-376. Thousand Oaks, CA: Sage.

Good, B.J.

1994 Medicine, Rationality, and Experience: An Anthropological Perspective. Cambridge: Cambridge University Press.

Gordon, D.

1988 Tenacious Assumptions of Western Medicine. In Biomedicine Examined. M. Lock and D. Gordon, eds., pp. 19-56. Dordrecht: Kluwer Academic.

Jenkins, J.H.

1998 Diagnostic Criteria for Schizophrenia and Related Psychotic Disorders: Integration and Suppression of Cultural Evidence in DSM-IV. Transcultural Psychiatry 35: 357-376.

Mishler, E.G.

1975 Studies in Dialogue and Discourse II: Types of Discourse Initiated and Sustained through Questioning. Journal of Psycholinguistic Research 4: 99-121.

Mishler, E.G.

1979 Meaning in Context: Is There Any Other Kind? Harvard Educational Review 49(1): 1-19.

Mishler, E.G.

1984 The Discourse of Medicine. Norwood, NJ: Ablex.

Mishler, E.G.

1986 Research Interviewing: Context and Narrative. Cambridge, MA: Harvard University Press.

Spitzer, R.L., J.B. Williams, M. Gibbon, and M.B. First

1992 The Structured Clinical Interview for DSM-III-R (SCID): I. History, Rationale, and Description. Archives of General Psychiatry 49(8): 624-629.

Spradley, J.P.

1979 The Ethnographic Interview. New York: Holt, Rinehart and Winston.

Spradley, J.P.

1980 Participant Observation. New York: Holt, Rinehart and Winston. 